\title{
Pregnancy implanted in the scar of caesarean section and the role of the general practitioner
}

\author{
Sarcina implantată în cicatricea de operație cezariană și \\ rolul medicului de familie
}

\author{
Ana Maria Alexandra Stănescu', Ioana Veronica Grăjdeanu', Gabriel Cristian Bejan', \\ Liviu Nicolae Ghilencea ${ }^{1}$, Mihaela Adela lancu ${ }^{1}$, Anca Angela Simionescu ${ }^{2,3}$ \\ ${ }^{1}$ Departamentul Medicină de Familie, Universitatea de Medicină și Farmacie „Carol Davila“, \\ București, România \\ ${ }^{2}$ Departamentul de Obstetrică și Ginecologie, Universitatea de Medicină și Farmacie \\ „Carol Davila“, București, România \\ ${ }^{3}$ Departamentul de Obstetrică-Ginecologie, Spitalul Clinic Filantropia, București, România
}

\begin{abstract}
The increase in the number of cesarean sections led to severe complications, such as the ectopic scar pregnancy and the morbidly adherent placenta. The incidence of scar pregnancy is $1 / 2000$ of pregnancies, the more frequently associated with the higher the number of cesarean sections.

These can cause severe bleeding, rupture of the uterus, bladder or digestive injury or maternal mortality. The general practitioner has an important role in the diagnosis and monitoring of these patients. He knows the patient's history, is asked in permanent by it and sometimes is in the situation of being the only one checking pregnancy. This work aims to review the diagnostic and monitoring criteria for ectopic scar pregnancy helpful to family physicians. Addressing all patients with a scarred uterus for early screening ultrasound may increase the rate of diagnosis. The family doctor is an essential partnership in monitoring these high risk cases.
\end{abstract}

Keywords: scar pregnancy, general practitioner, family doctor, cesarean section complications

\section{REZUMAT}

Creșterea numărului de operații cezariene a dus la apariția unor complicații severe și anume la sarcina implantată pe cicatricea de operație cezariană și la placenta cu aderență anormală. Incidența sarcinii pe cicatricea de cezariană este de 1/2.000 de sarcini, cu atât mai frecventă cu cât există un număr mai mare de operații cezariene în antecedente.

Acestea pot determina hemoragii severe, ruptură uterină, plăgi vezicale sau ale organelor digestive până la decesul pacientei. Medicul de familie are un rol important în diagnosticarea și monitorizarea acestor paciente. El cunoaște istoricul pacientei, este solicitat în permanență de aceasta și uneori este în situația de a fi singurul care supraveghează sarcina. Acest articol revede criteriile de diagnostic și monitorizare ale sarcinii ectopice pe cicatricea de operație cezariană utile medicilor de familie. Abordarea tuturor pacientelor cu utere cicatriciale pentru ecografia precoce a sarcinii va crește rata de diagnosticare a acestor cazuri. Medicul de familie este o verigă esențială în monitorizarea acestor cazuri cu risc crescut.

Cuvinte cheie: sarcină pe cicatrice, medic generalist, medic de familie, complicații ale operaţiei cezariene

\section{INTRODUCERE}

Creșterea numărului de operații cezariene a dus la apariția unor complicații caracteristice: sarcina implantată pe cicatricea de operație cezariană și placenta cu aderență anormală. Sarcina implantată pe operația cezariană reprezintă implantarea blas- 
tocistului intramurală, în afara cavității uterine, la nivelul țesutului fibros miometrial al cicatricei de operație cezariană (1-3).

În această situație sarcina nu poate să se dezvolte normal, această entitate fiind considerată sarcină ectopică, patologică.

Primul caz a fost raportat accidental în 1978 după un avort la cerere soldat cu hemoragie și complicații, considerat ca fiind o eroziune a vaselor sanguine (4). Fiind o sarcină ectopică localizată la nivel uterin, foarte multe cazuri scapă diagnosticului precoce.

Incidența raportată este de $1 / 2.000$ de cezariene, 1/3.000 de nașteri sau în caz de fertilizare in vitro 1/1688 sarcini (5-7). Sarcina implantată în cicatricea de operație cezariană reprezintă $6 \%$ dintre sarcinile ectopice la pacientele cu cel puțin o operație cezariană în antecedente $(8,9)$.

Medicul de familie care cunoaşte istoricul pacientei trebuie să fie atent la cazurile care prezintă utere cicatriceale și să examineze cu acuratețe rezultatul ecografiei.

Aceste două entități, sarcina ectopică pe cicatricea de operație cezariană și placenta cu aderență anormală, se pot complica cu ruptură uterină, hemoragie masivă în timpul sarcinii și al nașterii care pot duce la decesul matern. Sarcina pe cicatricea de operație cezariană este considerată precursorul placentei cu aderență anormală (10). Ideal ar fi ca aceste patologii să fie diagnosticate din primele săptămâni de gestație și sarcinile să fie întrerupte în scop terapeutic. În acest moment nu există standardizarea conduitei pentru aceste situații și, de multe ori, medicul de familie, alături de ginecolog, este implicat în consilierea pacientei. În unele situații, sarcina este monitorizată de medicul de familie şi, în unele cazuri, chiar acesta efectuează prima ecografie din sarcină, cea de diagnosticare a sarcinii.
Scopul acestui minireview este să prezinte medicului de familie informații practice legate de sarcina implantată pe operația de cezariană.

\section{DEFINIŢIE ŞI CLASIFICARE}

După fecundare, blastocistul se implantează în mod normal la nivel endometrial, penetrează miometrul și determină remodelarea vasculară utilă pentru dezvoltarea fetală. Dezvoltarea și invazia trofoblastului determină decidualizarea și formarea placentei. Decidualizarea endometrială nu implică neapărat prezența blastocistului, ea producându-se și pentru sarcinile ectopice și extrauterine (11). Studii moleculare au arătat faptul că în sarcina ectopică decidualizarea endometrială este mai slabă (12). În cazul uterelor cicatriciale există un defect sau o lipsă a deciduei la nivelul cicatricei, o nişă, care determină ca după implantarea blastocistului la acest nivel să se producă mecanisme diferite de o decidualizare normală (13) şi vilusurile coriale să vină în contact cu miometrul (10). Incidența istmocelului, a nișei variază între 25 şi $84 \%$ (14) şi s-ar datora unor factori care țin de tehnica operatorie a cezarienei, de infecțiile postoperatorii sau de patologii materne sau alterări ale colagenului.

Atât pacientele. cât și doctorii afirmă că prima cezariană se vindecă fără nicio complicație. Dar vindecarea cicatricei de operaţie cezariană este responsabilă de sarcina pe cicatricea de operație cezariană, de sindromul de nişă din afara sarcinii $(15,16)$.

Așa cum se poate observa în Figura 1, sarcina pe cicatrice poate fi parțială - când există o legătură cu cavitatea uterină - și sarcina completă pe cicatricea de operație cezariană, cînd nu există niciun fel de comunicare cu cavitatea uterină.

\section{SARCINA PARTIALA PE CICATRICEADE OPERATIE CEZARIANA}

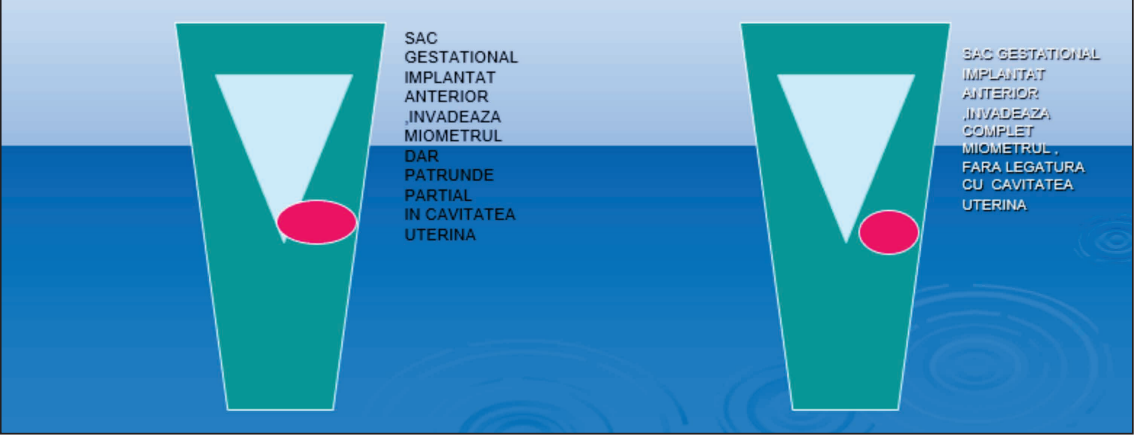

SARCINA COMPLETA PE CICATRICEA DE OPERATIE CEZARIANA
FIGURA 1. Tipurile de sarcină ectopică pe cicatricea de operație cezariană 
După progresia în timp și legătura cu cavitatea uterină, cele două tipuri de sarcini pe cicatricea de operație cezariană sunt tipul 1 endogenic (cu progresie spre spațiul cervico-istmic și cavitatea uterină - poate evolua ca o sarcină intrauterină cu sângerare), tipul 2 exogenic (cu progresie spre vezica urinară și cavitatea abdominală - poate evolua cu ruptură uterină și hemoragie masivă).

În cazul în care se tratează conservator, cazurile izolate au arătat că există un risc de recurență (19).

\section{DIAGNOSTIC CLINIC ŞI ECOGRAFIC}

Diagnosticul clinic este similar cu cel din sarcina extrauterină tubară, tabloul caracteristic cuprinde amenoree, durere și metroragie. O importanță deosebită trebuie acordată antecedentelor personale ale pacientei cu istoric de cezariană (cezariene) sau manevre intrauterine - chiuretaje, histeroscopii.

O situație frecventă este diagnosticarea în afara oricărui simptom, când pacienta se prezintă pentru ecografia de constatare a sarcinii; în acest caz, de obicei se pot rata diagnosticele. $13 \%$ dintre diagnosticele sarcinilor pe cicatricea de cezariană asimptomatice sunt ratate (18). Într-un review s-a arătat că, dintre 751 cazuri de sarcină pe cicatrice analizate, $107 \mathrm{au}$ fost nediagnosticate (20). Aceasta se datorează și faptului că o treime dintre cazuri sunt asimptomatice $(21,22)$.

Este bine cunoscut faptul că sarcina intrauterină se diagnostichează ecografic, transvaginal și transabdominal, de la valori ale betaHCG (hormonul gonadotropin corionic) peste $100 \mathrm{UI} / \mathrm{dl}$. Semnele ecografice sunt: sac gestațional cu dublă coroană trofoblastică, veziculă vitelină și embrion cu activitate cardiacă. Dubla coroană trofoblastică este un semn de certitudine al sarcinii intrauterine (Figura 2). Un studiu prospectiv pe 79 participanți a demonstrat că semnul de dublă coroană trofoblastică este prezent în 100\% dintre cazurile de sarcină intrauterină. Dacă semnul este absent, probabilitatea ca sarcina să fie ectopică este de $66 \%$, aceasta fiind valoarea sa predictiv negativă (23).

Dubla coroană trofoblastică trebuie diferențiată de pseudosacul din sarcina ectopică (24), pseudosacul fiind deformabil de la o examinare la alta și variind ca dimensiune.

$\mathrm{O}$ atenție particulară pentru diagnosticul ecografic al sarcinii localizate pe cicatricea de operație cezariană (Figura 3) trebuie acordată localizării trofoblastice și placentare, care este întotdeauna pe niṣa cezarienei.

De asemenea, Timor-Trisch şi colab. au descris faptul că împărțirea uterului în cadrane și fixarea

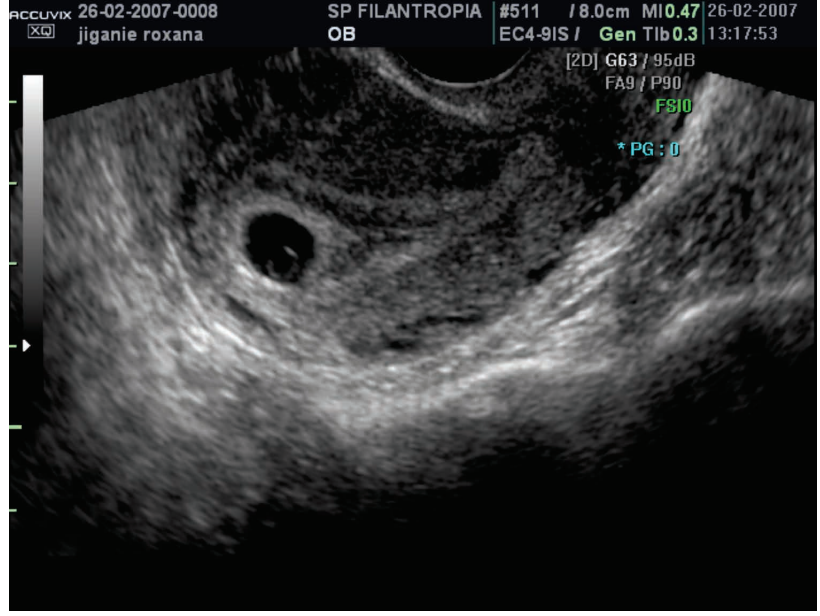

FIGURA 2. Sarcină intrauterină incipientă: Sacul gestațional cu dubla coroană şi vezicula vitelină

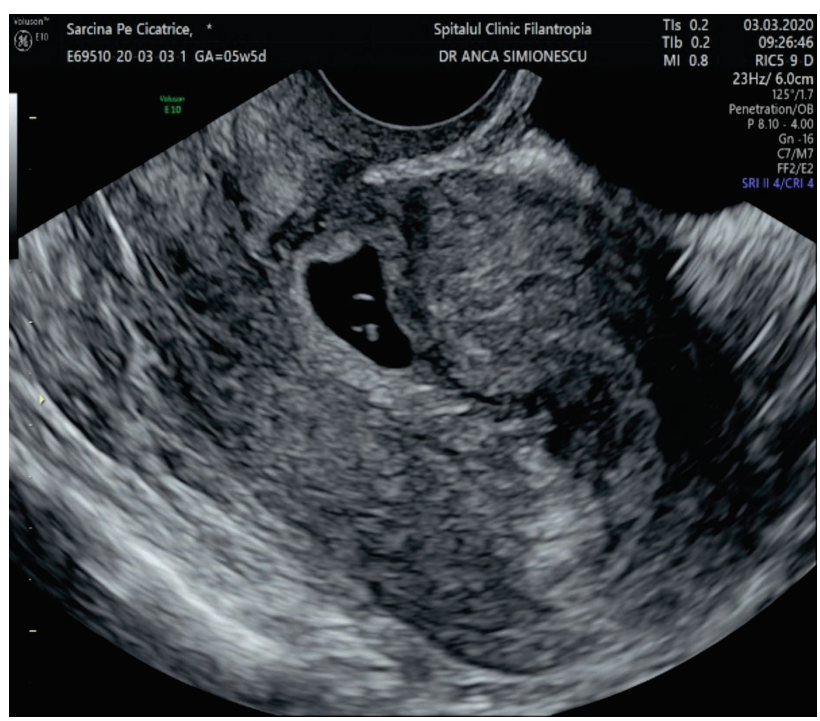

FIGURA 3. Sarcină localizată pe cicatricea de operație cezariană

centrului uterin ajută la diagnosticarea sarcinii pe cicatricea de operație cezariană, aceasta fiind localizată mult deasupra centrului uterin (10).

În cazul în care se suspicionează o sarcină ectopică pe cicatricea de operație cezariană, pacienta trebuie adresată de urgență unui spital cu departament de medicină-materno-fetală si serviciu de bloc operator de ginecologie și anestezie terapieintensivă pentru confirmare și tratament. Trebuie să i se explice riscurile de ruptură uterină și hemoragie și, poate, cel mai important, utilitatea avortului în cazul acestor sarcini pentru a evita complicațiile. Din păcate, ghidurile actuale nu se referă la aceste opțiuni, dar în România avortul la cerere poate fi efectuat pîna la 14 săptămâni (Art. 21 Noul Cod Penal). De asemenea, medicul de familie ar trebui să informeze pacientele cu utere cicatriceale să se adreseze pentru ecografia din trimestrul 1 pentru verificarea placentară, chiar dacă 
aceste paciente nu doresc efectuarea screeningului prenatal.

\section{ROLUL MEDICULUI DE FAMILIE ÎN TRATAMENTUL DE SPECIALITATE}

Tratamentul de specialitate se va efectua obligatoriu în spitale de ginecologie care au servicii de bloc operator. Pacienta trebuie să rămână în contact cu echipa medicală și să se prezinte la spital ori de cîte ori situaţia o impune.

O cincime dintre aceste cazuri se opresc din evoluţie şi pacienta trebuie supravegheată pentru a fi siguri de eliminarea completă a produsului de concepție neviabil.

Tratamentul poate fi medical, prin administrarea Metotrexatului combinat sau nu cu chiuretajul uterin sau rezecția histeroscopică sau laparoscopică a sarcinii.

Există un risc de recurență în caz de tratament conservator.

Pacientele care decid să continue sarcina vor fi informate despre riscurile sarcinii cu placentă cu aderență anormală: hemoragie, plăgi ale organelor din vecinătatea uterului - vezica urinară, uretere, plăgi digestive, inclusiv riscul de deces matern.

Conflict of interest: none declared

Financial support: none declared

\section{$\overline{\text { BIBLIOGRAFIE }}$}

1. Le A, Shan L, Xiao T, Zhuo R, Xiong H, Wang Z. Transvaginal surgical treatment of cesarean scar ectopic pregnancy. Arch Gynecol Obstet. 2013 Apr;287(4):791-6.

2. Birch Petersen K, Hoffmann E, Rifbjerg Larsen C, Svarre Nielsen H. Cesarean scar pregnancy: a systematic review of treatment studies. Fertil Steril. 2016 Apr;105(4):958-67.

3. ESHRE working group on Ectopic Pregnancy, Kirk E, Ankum P, Jakab A, Le Clef N, Ludwin A, Small R, Tellum T, Töyli M, Van den Bosch $T$, Jurkovic $D$. Terminology for describing normally sited and ectopic pregnancies on ultrasound: ESHRE recommendations for good practice. Hum Reprod Open. 2020 Dec 16;2020(4):hoaa055.

4. Larsen JV, Solomon MH. Pregnancy in a uterine scar sacculus--an unusual cause of postabortal haemorrhage. A case report. S Afr Med J. 1978 Jan 28;53(4):142-3.

5. Donnez O. Cesarean scar defects: management of an iatrogenic pathology whose prevalence has dramatically increased. Fertil Steril. 2020 Apr;113(4):704-716.

6. Grechukhina O, Deshmukh U, Fan L, Kohari K, Abdel-Razeq S, Bahtiyar MO, Sfakianaki AK. Cesarean Scar Pregnancy, Incidence, and Recurrence: Five-Year Experience at a Single Tertiary Care Referral Center. Obstet Gynecol. 2018 Nov;132(5):1285-1295.

7. Maymon R, Svirsky R, Smorgick N, Mendlovic S, Halperin R, Gilad $\mathrm{K}$, Tovbin J. Fertility performance and obstetric outcomes among women with previous cesarean scar pregnancy. J Ultrasound Med. 2011 Sep;30(9):1179-84.

8. Seow KM, Huang LW, Lin YH, Lin MY, Tsai YL, Hwang JL. Cesarean scar pregnancy: issues in management. Ultrasound Obstet Gynecol. 2004 Mar;23(3):247-53.

9. Parker VL, Srinivas M. Non-tubal ectopic pregnancy. Arch Gynecol Obstet. 2016 Jul;294(1):19-27.
O colaborare cu spitale pluridisciplinare care să aibă serviciu de radiologie intervențională pentru embolizarea arterelor uterine este esențială.

\section{CONCLUZII}

Indiferent de conduita medicală, aceste patologii trebuie diagnosticate cu atenție și este foarte important ca pacienta să înțeleagă riscurile potențiale și să se prezinte de urgență la spital de câte ori situația o impune. Medicul de familie este una dintre verigile importante, care adresează pacientele cu uter cicatriceal la ecografia de confirmare a sarcinii. De asemenea, în situaţia în care pacienta are acces doar la supravegherea efectuată de către medicul de familie, acesta trebuie să fie capabil să ridice suspiciunea de sarcină pe cicatricea de operație cezariană și să orienteze rapid pacienta către o instituţie medicală corespunzătoare. Medicul de familie are, de asemenea, un rol important în supravegherea pacientelor care au avut complicații, prezintă anemie sau plăgi ale vezicii urinare.

10. Timor-Tritsch IE, Monteagudo A, Calì G, D'Antonio F, Kaelin Agten A. Cesarean Scar Pregnancy: Diagnosis and Pathogenesis. Obstet Gynecol Clin North Am. 2019 Dec;46(4):797-811.

11. Finn CA. Why do women menstruate? Historical and evolutionary review. Eur J Obstet Gynecol Reprod Biol. 1996 Dec;70(1):3-8.

12. Horne AW, van den Driesche S, King AE, Burgess S, Myers M, Ludlow H, Lourenco P, Ghazal P, Williams AR, Critchley HO, Duncan WC. Endometrial inhibin/activin beta-B subunit expression is related to decidualization and is reduced in tubal ectopic pregnancy. $\mathrm{J}$ Clin Endocrinol Metab. 2008 Jun;93(6):2375-82.

13. Tantbirojn P, Crum CP, Parast MM. Pathophysiology of placenta creta: the role of decidua and extravillous trophoblast. Placenta. 2008 Jul;29(7):639-45.

14. Bij de Vaate AJ, van der Voet LF, Naji O, Witmer M, Veersema S, Brölmann HA, Bourne T, Huirne JA. Prevalence, potential risk factors for development and symptoms related to the presence of uterine niches following Cesarean section: systematic review. Ultrasound Obstet Gynecol. 2014 Apr;43(4):372-82.

15. Timor-Tritsch IE, Monteagudo A, Cali G, Vintzileos A, Viscarello R, Al-Khan A, Zamudio S, Mayberry P, Cordoba MM, Dar P. Cesarean scar pregnancy is a precursor of morbidly adherent placenta. Ultrasound Obstet Gynecol. 2014 Sep;44(3):346-53.

16. Fylstra DL. Ectopic pregnancy within a cesarean scar: a review. Obstet Gynecol Surv. 2002 Aug;57(8):537-43.

17. Jurkovic D, Hillaby K, Woelfer B, Lawrence A, Salim R, Elson CJ. First-trimester diagnosis and management of pregnancies implanted into the lower uterine segment Cesarean section scar. Ultrasound Obstet Gynecol. 2003 Mar;21(3):220-7.

18. Timor-Tritsch IE, Monteagudo A. Unforeseen consequences of the increasing rate of cesarean deliveries: early placenta accreta and 
cesarean scar pregnancy. A review. Am J Obstet Gynecol. 2012 Jul;207(1):14-29.

19. Holland MG, Bienstock JL. Recurrent ectopic pregnancy in a cesarean scar. Obstet Gynecol. 2008 Feb;111(2 Pt 2):541-5.

20. Ko JK, Li RH, Cheung VY. Caesarean scar pregnancy: a 10-year experience. Aust N Z J Obstet Gynaecol. 2015 Feb;55(1):64-9.

21. Rheinboldt M, Osborn D, Delproposto Z. Cesarean section scar ectopic pregnancy: a clinical case series. J Ultrasound. 2015; 18:191-5.

22. Liu H, Leng J, Shi H, Lang J. Expectant treatment of cesarean scar pregnancy: two case reports and a glimpse at the natural courses. Arch Gynecol Obstet. 2010 Oct;282(4):455-8.
23. Richardson A, Hopkisson J, Campbell B, Raine-Fenning N. Use of double decidual sac sign to confirm intrauterine pregnancy location prior to sonographic visualization of embryonic contents. Ultrasound Obstet Gynecol. 2017 May;49(5):643-648.

24. Bradley WG, Fiske CE, Filly RA. The double sac sign of early intrauterine pregnancy: use in exclusion of ectopic pregnancy. Radiology. 1982 Apr;143(1):223-6. 